\title{
PENERAPAN ARTIFICIAL INTELLIGENCE PADA GAME 2D CAT Vs Dog MENGGUNAKAN Finite StaTe MACHINE BERBASIS ANDROID
}

\author{
Putra Prima Arhandi ${ }^{1}$, Arief Prasetyo ${ }^{2}$, Ridwan Rismanto ${ }^{3}$ \\ ${ }^{1,2,3)}$ Program Studi Teknik Informatika, Jurusan Teknologi Informasi Politeknik Negeri Malang \\ Jalan Soekarno Hatta no 9 Malang Telp (0341) 404424 Fax (0341) 404420 \\ e-mail: ${ }^{1)}$ putraprima@polinema.ac.id, ${ }^{2}$ arief.prasetyo@polinema.ac.id, ${ }^{3)}$ rismanto@polinema.ac.id
}

\begin{abstract}
Abstrak : Abstrak yang dipersiapkan dengan baik, memungkinkan pembaca untuk mengidentifikasi konten dasar dari dokumen dengan cepat dan akurat, untuk menentukan relevansinya dengan kepentingan mereka, dan dengan demikian mereka dapat memutuskan apakah akan membaca dokumen secara keseluruhan atau tidak. Abstrak harus informatif dan benar-benar jelas, memberikan pernyataan yang jelas apa permasalahan yang ada, pendekatan atau solusi yang diusulkan, dan menunjukkan temuan utama dan simpulan. Panjang abstrak harus dalam 100 sampai 150 kata. Abstrak harus ditulis dalam bentuk lampau. Standar nomenklatur harus digunakan dan singkatan harus dihindari. Tak ada pengutipan dalam abstrak. Daftar kata kunci memberikan kesempatan untuk menambahkan kata kunci, yang digunakan untuk layaan pengindeks-kan dan pengabstrakan, di samping yang sudah ada dalam judul. Sangat bijaksana menggunakan kata kunci yang dapat meningkatkan kemudahan dari pihak yang berkepentingan untuk dapat menemukan artikel kita.
\end{abstract}

Kata kunci: maksimal 5 kata terpenting dalam makalah

\begin{abstract}
A well-prepared abstract enables the reader to identify the basic content of a document quickly and accurately, to determine its relevance to their interests, and thus to decide whether to read the document in its entirety. The Abstract should be informative and completely self-explanatory, provide a clear statement of the problem, the proposed approach or solution, and point out major findings and conclusions. The Abstract should be 100 to 150 words in length. The abstract should be written in the past tense. Standard nomenclature should be used and abbreviations should be avoided. No literature should be cited. The keyword list provides the opportunity to add keywords, used by the indexing and abstracting services, in addition to those already present in the title. Judicious use of keywords may increase the ease with which interested parties can locate our article.
\end{abstract}

Keywords: maximum 5 keywords from paper

\section{PENDAHULUAN}

Perkembangan teknologi telah mengantarkan kita sampai kepada era mobile dimana semua komputasi yang dapat dilakukan oleh komputer / pc pada jaman dahulu juga dapat dilakukan oleh perangkat mobile seperti handphone atau tablet. Perkembangan ini juga diikuti oleh developer game dimana banyak sekali bermunculan game berbasis mobile yang sangat populer.

Game berbasis mobile ini juga memiliki berbagai macam genre dan tipe gaya permainan pada umumnya game tersebut biasanya memiliki NPC (Non Player Character), NPC adalah sebuah karakter game yang tidak dapat dikontrol oleh pemain semua hal yang dilakukan oleh NPC murni di kontrol oleh mesin (komputer).(Warpefelt 2016)

Pada NPC ini lah banyak sekali diterapkan sebuah logika atau metode Artificial Intelligence salah satunya menggunakan finite state machine untuk mengatur pergerakan NPC pada game dengan tema pertanian dan peternakan, pada game ini dilakukan penerapan finite state machine pada beberapa NPC. Pada game tersebut finite state machine di pasangkan ke karakter pandai besi, karakter saingan yaitu Barney dan Max, serta pada karakter NPC lain yaitu Zack (pandai besi), Patrick (kepala desa) dan Anna (penjaga toko). Finite state machine cocok diterapkan pada game ini karena bertema Role Playing Game 
dan memberikan sebuah kecerdasan buatan yang sederhana kepada NPC untuk merespon perlakuan dari player (Rositaningsih 2013).

Pada penelitian selanjutnya finite state machine juga digunakan pada sebuah game adventure pengenalan unsur kimia, dimana pada game ini fsm dipasang pada NPC musuh, musuh pada game ini terdiri dari 3 musuh yaitu musuh $\mathrm{A}$, musuh $\mathrm{B}$ dan musuh $\mathrm{C}$, musuh musuh pada game ini memiliki behavior yang berbeda terhadap karakter utama. Musuh A memiliki fsm yang paling sederhana dengan memiliki 3 state dan 2 parameter action, yaitu jarak dan health player utama. (Bimantoro 2016).

Berdasarkan penelitian diatas maka pada penelitian ini kami mencoba membuat sebuah game 2D bergenre archade / fighting yang terdiri dari 2 karakter berbeda yang menyerang saling bergantian. FSM diterapkan pada NPC ketika pemain memilih mode permainan Single Player Mode. FSM diterapkan pada game ini dengan harapan dapat membuat game yang dibuat menjadi lebih menarik dan menyenangkan untuk dimainkan.

\section{MetOde PENELITIAN}

\subsection{Finite State Machine}

Dalam perancangan Artificial Intelegent untuk game, state machine merupakan teknik yan g paling banyak digunakan untuk permasalahan " decision making" dan sekaligus dengan scriptingnya juga digunakan secara luas untuk merancang system decision making dalam game. State machine dikenal secara luas sebagai teknik untuk pemodelan fenomena atau ko ndisi berbasis event, termasuk penguraiannya, serta desain interface. FSM (Finite State Machine ) atau juga disebut sebagai teknik yang secara luas dipergunakan dalam merancang AI dalam game. Teknik ini merupakan metodologi perancangan system untuk memodelk an perilaku (behavior) dari si stem atau objek yang kompleks dengan kondisi yang telah didefinisikan dalam satu set. Menurut Ian Millington [2006] dalam bukunya yang berjudul Artificial Itelligence for Games menyebutkan bahwa Finite State Machines (FSM) m asuk dalam ranah Decision Making (pembuat keputusan) pada Artificial Intelligence (AI). Dalam FSM masing - masing karakter menempati satu state. Biasanya, tindakan atau perilaku yang terkait dengan masing - masing state. Jadi selama karakter tetap dalam keadaan itu, ia akan terus melakukan tindakan yang sama. State terhubung bersama oleh transition. Setiap transition mengarah dari satu state ke state lain yang biasanya state tujuan state target ini disebut dengan action dan masing - masing memiliki se perangkat kondisi yang terkait. Jika permainan menentukan bahwa kondisi transition terpenuhi, maka karakter berubah dari state ke state target (action) melalui transition itu.

FSM melacak himpunan state yang ada kemudian inputan masuk ke $\mathrm{m}$ asing - masing state, serangkaian keadaan transition tetap. Setiap transition dapat diimplementasikan dengan kondisi yang sesuai. Pada setiap iterasi(biasanya setiap frame), fungsi update FSM digunakan. Ini memeriksa untuk melihat apakah ada perubahan transition dari kondisi saat dipicu oleh inputan. Kemudian menyusun daftar action dari negara yang sedang aktif. Jika transition telah menemukan action yang dituju, maka transition be rhenti. (Ian Millington : 2006)

Gambar prinsip dari komponen-komponen yang terintegrasi dalam FSM pada gambar 2.1:

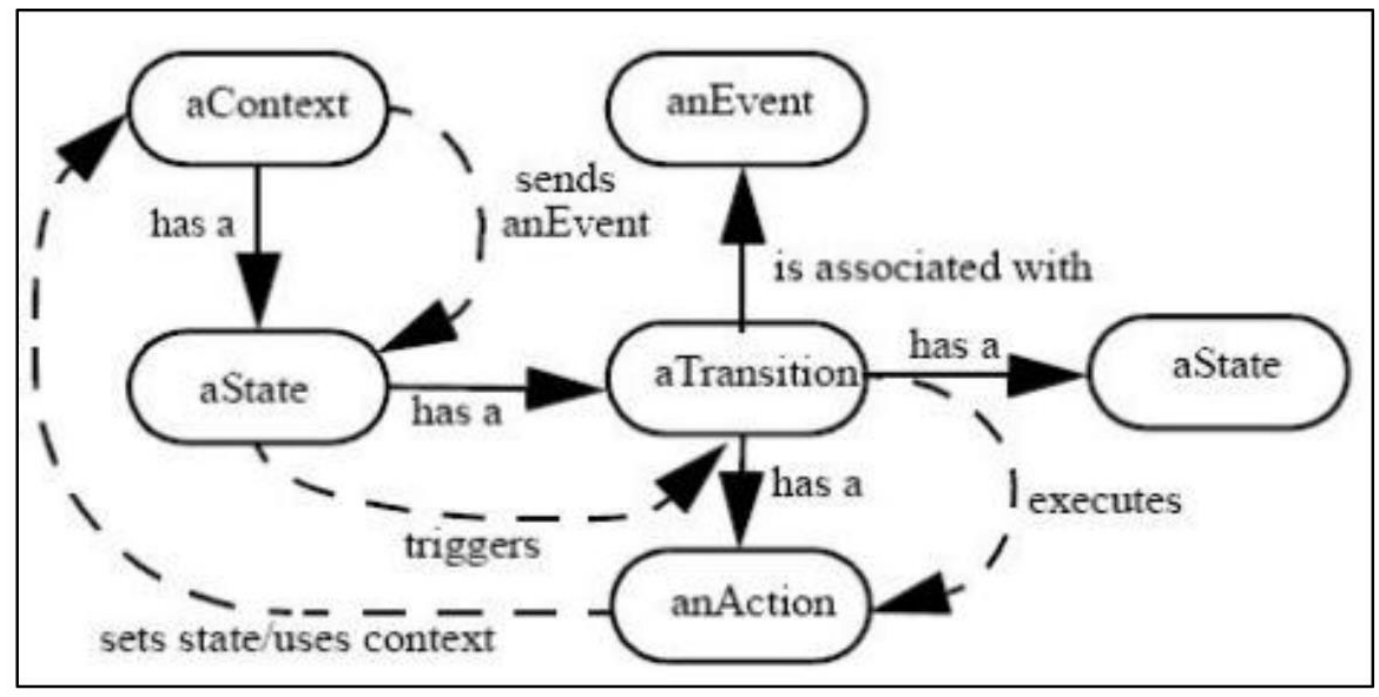


Finite State Machine (FSM) adalah membagi sebuah respon objek game kedalam bagian - bagian (state) sehingga objek te rsebut memilikki bagian untuk setiap respon objek game.Implementasi tersebut menghasilkan suatu urutan scenario tertentu pada game.Sehingga dalam game akan terdapat alur permainan yang harus di lewati nantinya yang dapat mendifisikan suatu set 29 kondisi ya ng menentukan kapan suatu bagian harus berubah ke bagian yang lain. (Rich :2009) finite state machine atau FSM adalah merupakan sebuah metodologi perancangan sisitem control yang mengambarkan tingkah laku atau prinsip kerja sistem dengan menggunakan tiga hal berikut : state (keadaan), event (kejadian) dan action (aksi) Pada satu saat dalam periode waktu yang cukup signifikan, sistem akan berada pada salah satu state yang aktif. Sistem dapat beralih atau bertransisi menuju state lain jika mendapatkan masukan atau event tertentu, baik yang berasal dari perangkat luar atau komponen dalam sistemnya itu sendiri (misal interupsi timer).

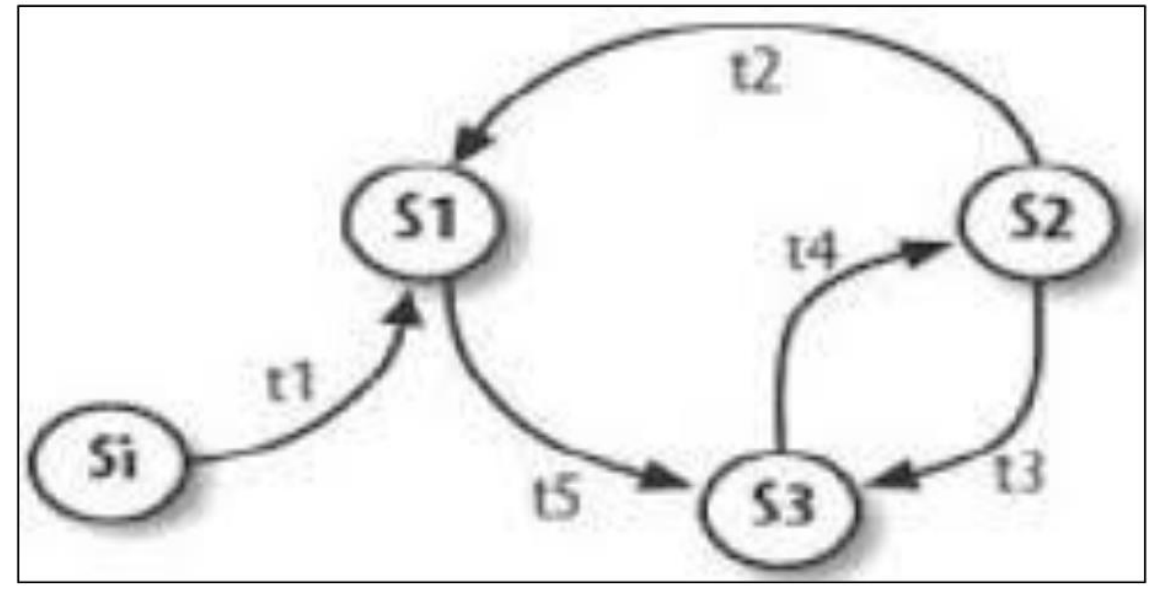

Pada Gambar 2.2 ter dapat 4 state $\{\mathrm{Si}, \mathrm{S} 1, \mathrm{~S} 2, \mathrm{~S} 3\}$ yang mungkin terjadi, setiap state - nya dapat berpindah state jika kondisi terpenuhi. Sebagai contoh state S1 dapat berpindah jika kondisi t5 terpenuhi. Dalam diagram ini, state - state yang terdapat pada sebuah sistem digambark an sebagai lingkaran yang diberi label unik, sedangkan transisi state yang diakibatkan oleh event tertentu direpresentasikan sebagai anak panah 30 yang berasal dari state yang ditinggalkan menuju state yang aktif. Setiap transisi yang terjadi umumnya juga dii kuti oleh aksi yang dilakukan oleh sistem yang dirancang. Secara praktis setiap diagram state yang dirancang akan selalu memiliki sebuah transisi awal (inisial) yang menuju salah satu state sejak sistem kontrol tersebut mulai dihidupkan. Diagram keadaan pada dasarnya merupakan salah satu bentuk representasi dari FSM. Diagram ini secara visual menggambarkan tingkah laku yang dimiliki oleh sistem kontrol yang kompleks kedalam bentuk yang lebih sederhana dan relative mudah dipahami. Dalam diagram ini, state - state yang terdapat pada sebuah sistem digambarkan sebagai lingkaran yang diberi label unik, sedangkan transisi state yang diakibatkan oleh event tertentu direpresentasikan sebagai anak panah yang berasal dari state yang ditinggalkan menuju state yang aktif

\subsection{Story Board}

Tahapan penelitian dimulai dengan melakukan pembuatan story board dan menentukan genre game yang akan dibuat, pada penelitian ini kami membuat game 2D bergenre archade dengan tema cat vs dog. Selanjutnya dilakukan pembuatan story board game yang akan dibuat. Setelah story board selesai dilanjutkan dengan melakukan penambahan AI pada NPC yang ada. Berikut ini story board yang digunakan pada pengembangan game 2D cat vs Dog 

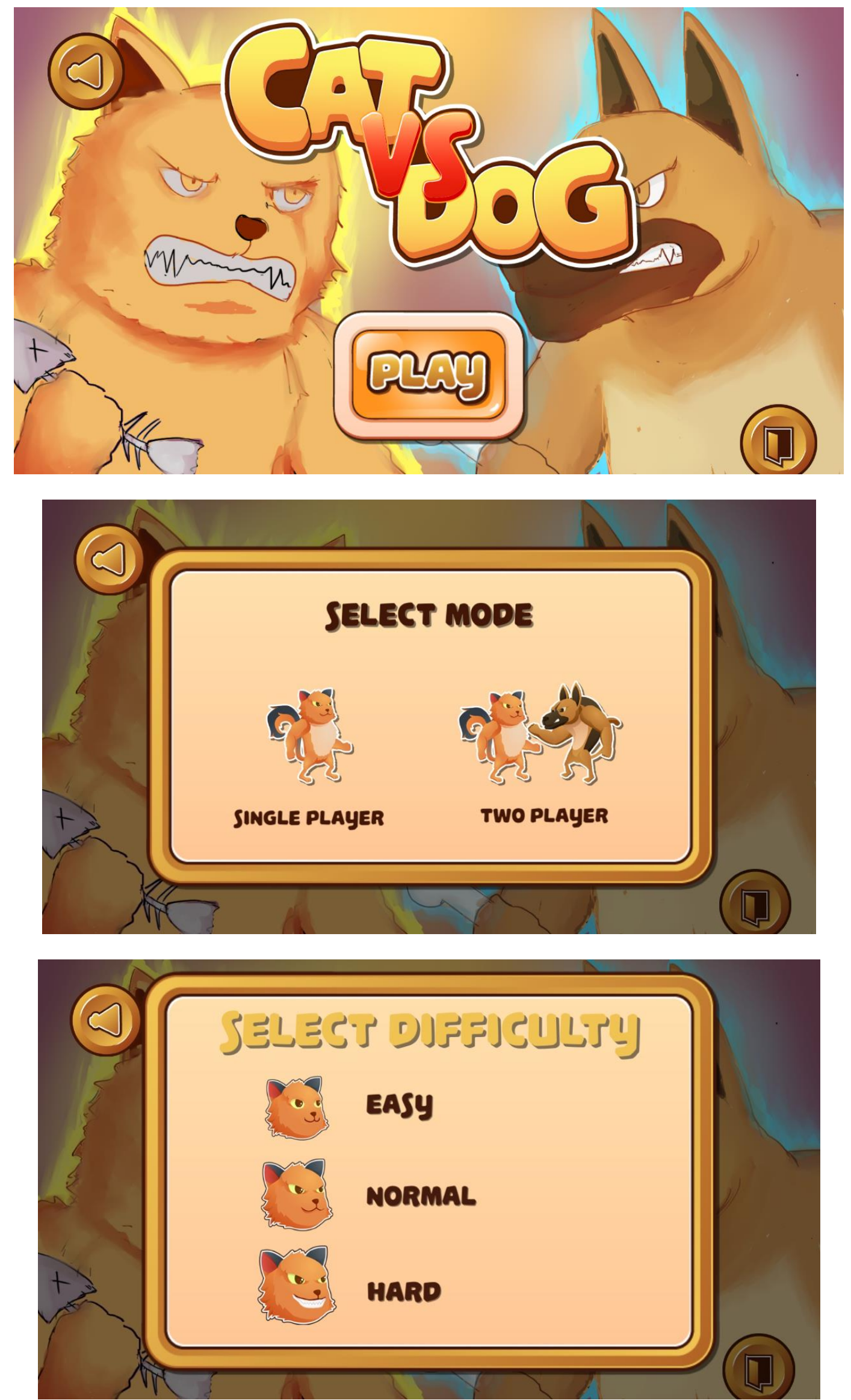


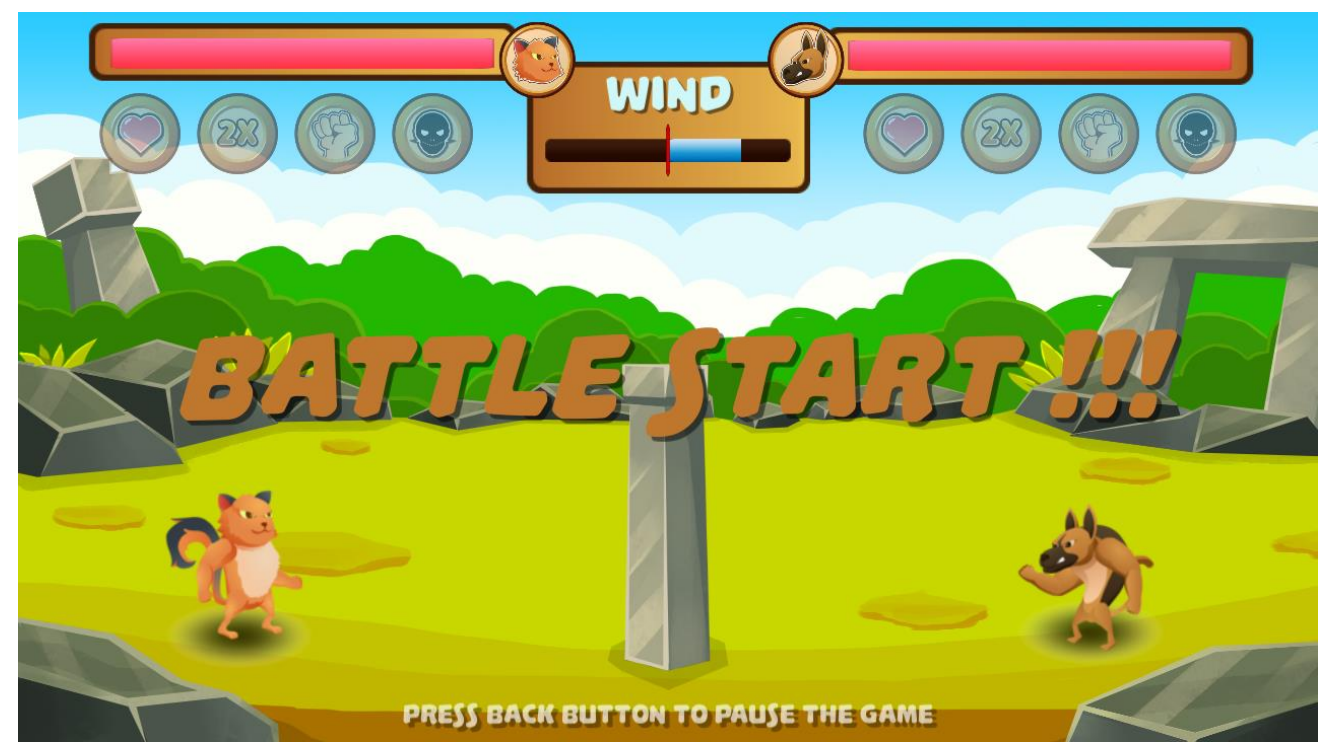

\subsection{Desain Finite State Machine}

Finite state machine pada game ini diterapkan untuk mengatur perilaku / gerakan yang dilakukan oleh pemain musuh (npc). Finite state machine yang dibuat dibagi menjadi tiga bagian yaitu level easy, level medium dan level hard. FSM pada masing masing level memiliki perbedaan yang signifikan baik dari segi actor maupun action yang dimiliki. Berikut ini diagram fsm untuk level easy.

Pada finite state machine untuk level easy terdapat 3 state yaitu lemparan kuat, lemparan random dan lemparan menengah lemparan dilakukan dengan beberapa syarat untuk lemparan random pada saat permainan untuk level easy npc akan melakukan lemparan sampai sebanyak 3 kali di awal pertandingan. Kemudian akan melakukan lemparan menengah jika counter sudah lebih dari 3 kali atau hitpoin masih tersisa 35\%. Khusus untuk lemparan kuat baru akan dilakukan setelah hitpoin kurang dari $35 \%$.

Sedangkan untuk level medium terdapat perbedaan yaitu pada syarat melakukan lemparan random, menengah dan lemparan kuatnya. Fsm untuk level medium dapat dilihat pada gambar berikut

Pada FSM untuk level medium terdapat perbedaan pada syarat lemparan menengah dimana lemparan menegah dilakukan apabila couter lebih besar dari 3 atau hitpoin berkurang sebanyak $50 \%$.

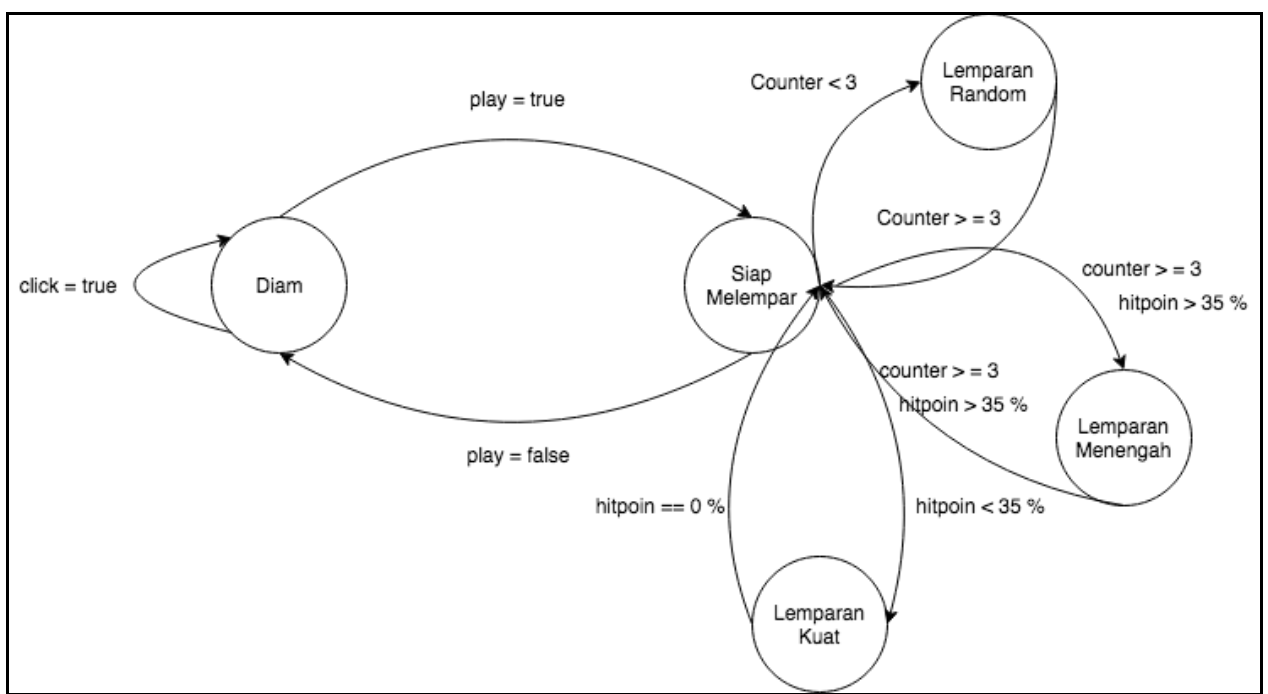




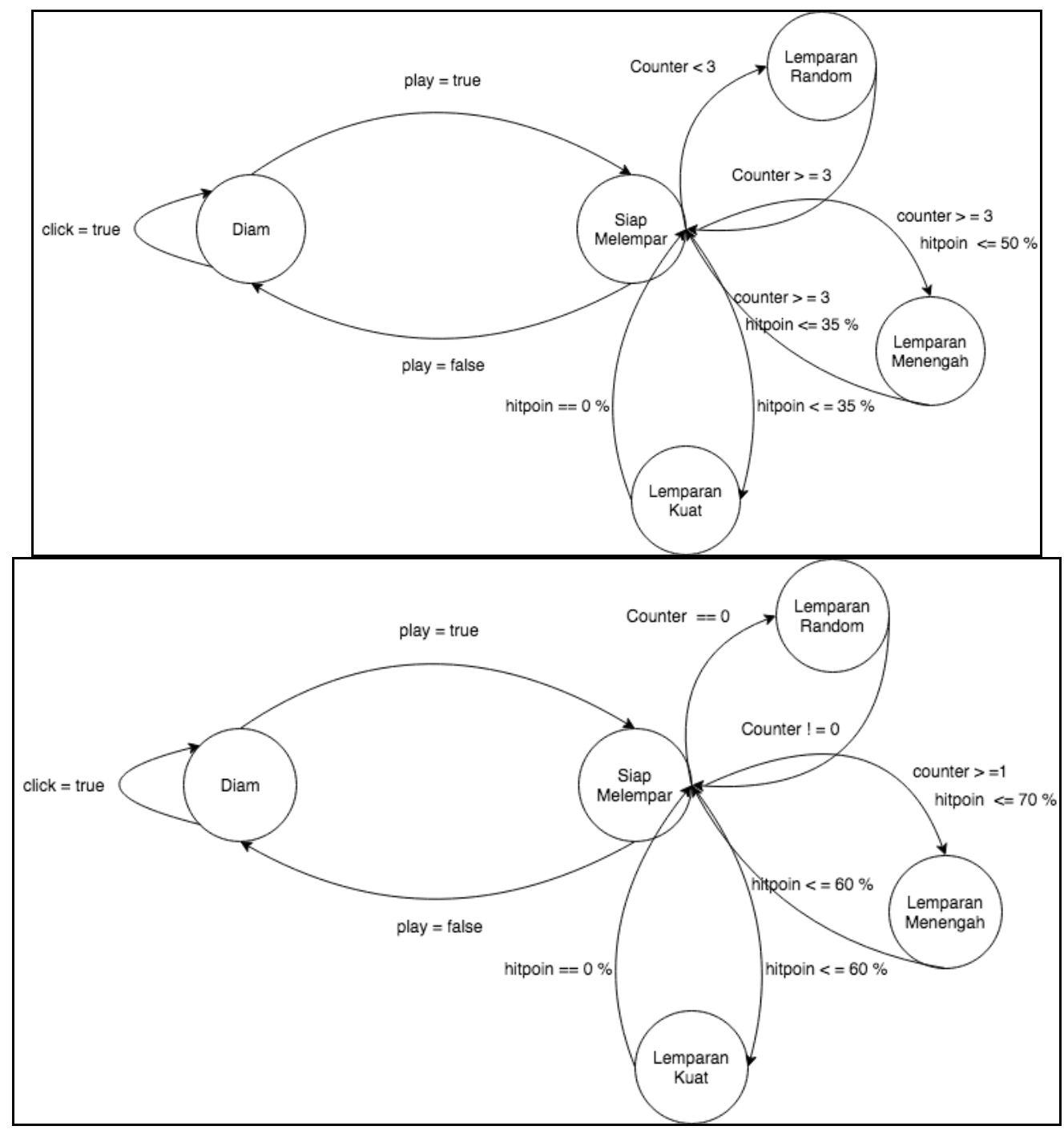

Sedangkan untuk level yang paling sulit yaitu level hard frekuensi kemunculan lemparan random diperkecil dan diperbanyak pada frekuensi lemparan menengah dan lemparan kuat.

\section{HASIL DAN PEMBAHASAN}

In this section, it is explained the results of research and at the same time is given the comprehensive discussion. Results can be presented in figures, graphs, tables and others that make the reader understand easily [2], [5]. The discussion can be made in several sub-chapters.

\section{KESIMPULAN}

Provide a statement that what is expected, as stated in the "Introduction" chapter can ultimately result in "Results and Discussion" chapter, so there is compatibility. Moreover, it can also be added the prospect of the development of research results and application prospects of further studies into the next (based on result and discussion).

\section{REFERENSI}

[1] Tito Bimantoro, Hanny Haryanto. Pemodelan Perilaku Musuh Menggunakan Finite State Machine (FSM) Pada Game Pengenalan Unsur Kimia. Journal of Applied Intelligent Syste. 2016;1(3):210219.

[2] Silvia Rostianingsih, Hans Kristian Wijaya, Gregorius Satia Budhi. Game Simulasi Finite State Machine Untuk Pertanian Dan Peternakan, Konferensi Nasional Sistem Informasi. Konferensi Nasional Sistem Informasi. 2013:9-15 
[3] Heinrik Warpefelt. The Non-Player Character Exploring the believability of NPC presentation and behavior. Sweeden : Departement of Computer and System Sciences. 2016.

[4] Pamela Mc Corduck. Machines Who Think: A Personal Inquiry into the History and Prospects of Artificial Intelligence. Canada : A K Peters, Ltd. 2008

[5] Andrew Rollings, Ernest Adams. Andrew Rollings and Ernest Adams on Game Design. Indianapolis : New Riders Publishing. 2003.

[6] Stuart Russel, Peter J Norvig. Artificial Intelligence : A Moderen Approach (3rd ed). New Jersey:Prentice Hall. 2009

[7] Davide Poole, Alan Maackworth, Randy Gebel. Computational Intelligence A Logical Approach. New York : Oxford University Press 1998. 